\title{
Design and Analysis of Chassis of Electric Solar Vehicle
}

\author{
Sadige Akhil Prasad \\ Mechanical Engineering \\ Sreenidhi Institute of Science and Technology \\ Hyderabad, India
}

\author{
Sai Kiran Maddela \\ Mechanical Engineering \\ Sreenidhi Institute of Science and Technology \\ Hyderabad, India
}

\begin{abstract}
Chassis act as a framework for supporting various parts of a vehicle. It needs to withstand twist, shock, vibration, and other stresses caused due to acceleration, braking, road condition, and shock initiated by other parts of a vehicle. It should carry a maximum load under all operating conditions. This paper depicts the design and scrutiny of the solar-powered car chassis. The investigation has been carried out, considering three different grades of SAE Steel grades (AISI). By utilizing data of all loads on in all possible direction are considered for designing an excellent chassis. The design and analysis are done using Solidworks and ANSYS
\end{abstract}

Keywords-SAE steel (AISI); chassis; solar-powered car; ANSYS; SOLIDWORKS

\section{INTRODUCTION}

A Chassis is an internal component of an automobile that supports all most all parts of an automobile. It is similar to a human skeleton. In recent years the design of chassis is drastically changed. The frame has to withstand shocks, vibrations. The design of the chassis is one of the timeconsuming part of designing a vehicle. In today's world, there is great demand and advancements in the field of the automobile industry. The solar-powered vehicle is alternate for fossil fuel-powered vehicles. In today's world, renewable energy sources play a more vital role than ever before. In addition to being clean and inexhaustible, they differ from fossil fuels chiefly in their diversity, potential, and abundance for use anywhere on the planet. With increasing awareness of climate change and environmental pollution, big corporations are investing funds for research in making sustainable energies affordable and feasible. In the last decade, significant technological advancements have been made in the same direction. The world is steering toward a sustainable future.

The preliminary design was made with the view of driver ergonomics. The design was made in SOLID WORKS, and analysis is done with the help of ANSYS 16. Based on the analysis, the modification was done, and the design was finalized.

Functions of Chassis

- To withstand the stresses acting on the car due to the bad road condition.

- To carry the load of the goods and passengers in the body of the car.

- To withstand the forces due to the sudden braking or acceleration by the driver.

\section{SPECIFICATION OF FRAME}

Based on the rule book considerations, inputs from other subsystems, and mechanical properties of the materials were considered. Hence, the design was finalized based on these parameters and made in SOLID WORKS. The analysis is done with the help of ANSYS 16. Based on the analysis, the modification was done, and the design was finalized.

The material chosen for the Chassis frame is AISI 4130 of 1inch diameter and $1.6 \mathrm{~mm}$ thickness based on its tensile strength, cost, density, weldability, bending strength, bending stiffness and

\section{CAD MODELLING}

Utilizing SOLIDWORKS software a suitable sustainable chassis model after numerous iteration and corrections.

\begin{tabular}{|c|c|}
\hline Specification & Value(inches) \\
\hline Wheel Base & 58 \\
\hline Track Width & 44 \\
\hline Height & 48 \\
\hline
\end{tabular}

Table 1: specification of chassis

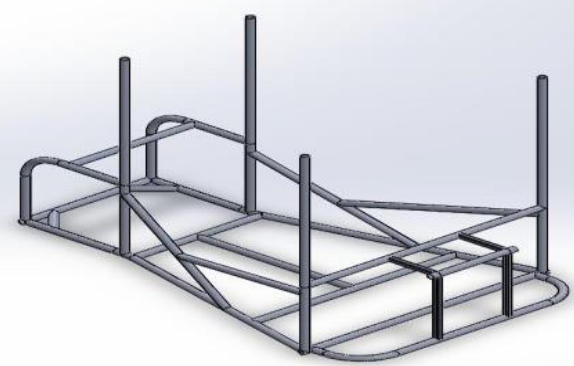

Figure 1: chassis isometric view

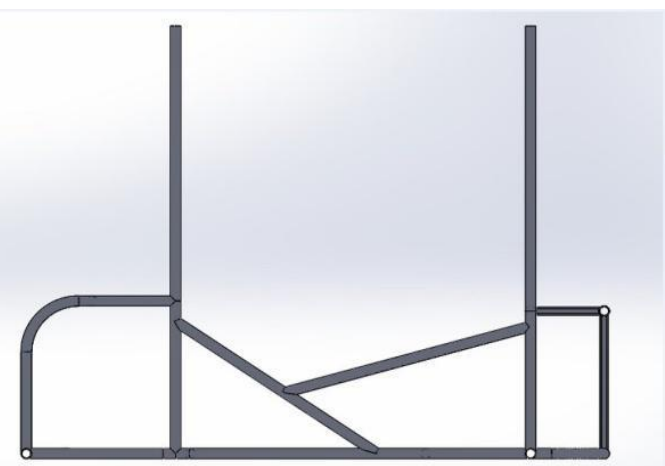

Figure 2: Chassis side view 


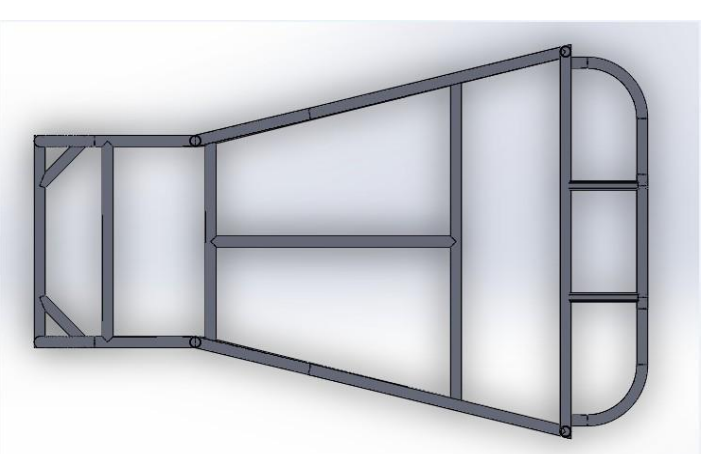

Figure 3: Chassis top view

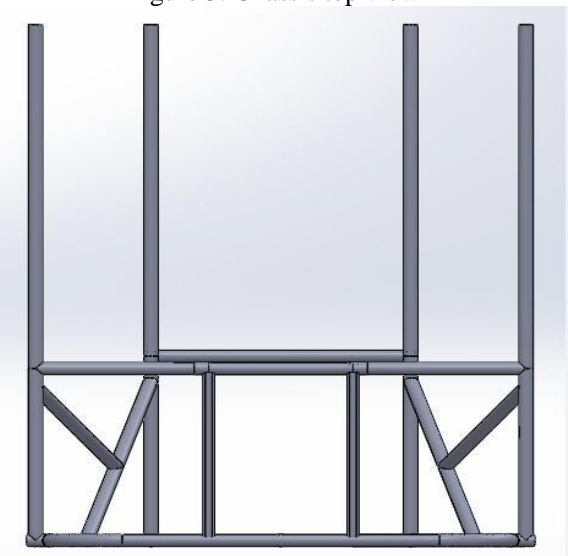

Figure 4: Chassis front view

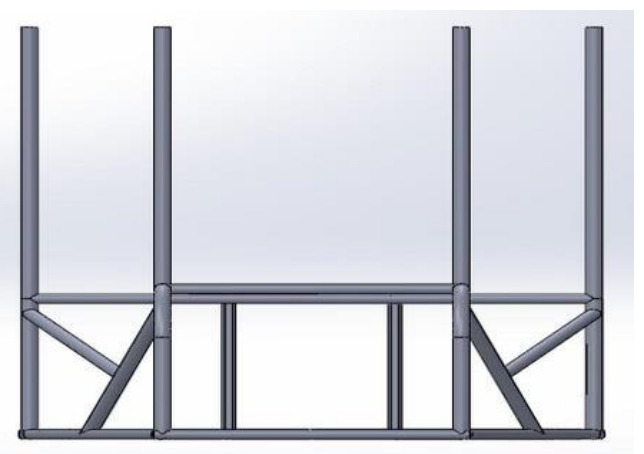

Figure 5: Chassis rear view

\section{MATERIALS}

The selection of chassis frame material is made based on tensile strength and also other parameters like cost, density, availability, weldability, bending strength, and bending stiffness. The percentage of carbon is more significant than $0.18 \%$.

The following materials are chosen for chassis:

i) AISI 1018 circular cross-section;

ii) AISI 1020 circular cross-section;

iii) AISI 4130 circular cross-section;

The chemical composition of the three materials is outlined in the following table.

\begin{tabular}{|c|c|c|c|}
\hline Element & AISI 1018 & AISI 4130 & AISI 1020 \\
\hline Manganese, $M n$ & $0.60-0.90$ & $0.7-0.9$ & $0.30-0.60$ \\
\hline Sulphur, S & $0.05(\max )$ & $0.04(\max )$ & $\leq 0.50$ \\
\hline Phosphorous, $\mathrm{P}$ & $0.04(\max )$ & $0.035(\max )$ & $\leq 0.040$ \\
\hline Chromium, Cr & - & $0.8-1.1$ & - \\
\hline
\end{tabular}

\begin{tabular}{|c|c|c|c|}
\hline Carbon, C & $0.15-0.20$ & $0.28-0.33$ & $0.17-0.23$ \\
\hline Silicon, $\mathrm{Si}$ & - & $0.15-0.35$ & - \\
\hline Iron, Fe & Balance & Balance & Balance \\
\hline Molybdenum, Mo & - & $0.15-0.25$ & - \\
\hline
\end{tabular}

Table 2: Chemical composition in three grades of AISI Properties of materials:

\begin{tabular}{|l|l|l|l|}
\hline Material & AISI 4130 & AISI 1018 & AISI 1020 \\
\hline Yield strength (MPa) & 365 & 350 & 460 \\
\hline $\begin{array}{l}\text { Ultimate tensile } \\
\text { strength }(\mathrm{MPa})\end{array}$ & 470 & 420 & 560 \\
\hline Density & 7.85 & 7.87 & 7.85 \\
\hline cost/meter & 500 & 330 & 310 \\
\hline weight $(\mathrm{kg} / \mathrm{m})$ & 0.93863 & 1.15651 & 0.93863 \\
\hline
\end{tabular}

Table 3: Physical properties of materials

\section{A. VOLUMETRIC ANALYSIS:-}

\section{CALCULATIONS}

Let $\mathrm{M} / \mathrm{L}$ be the mass per unit length of the crosssection.

Let $\mathrm{A}$ be the cross-sectional area, $\mathrm{d}_{\mathrm{i}}, \mathrm{d}_{\mathrm{o}}$, be the inner and outer diameter of the cross-section, and $\rho$ be the material density.

$$
\begin{aligned}
& \frac{M}{L}=\rho *_{\frac{\Pi}{4}} *\left(d_{0}^{2}-d_{i}^{2}\right) \\
& \text { i) For AISI } 1018 \text { (1.6mm thickness) } \\
& \rho=7.85 \mathrm{~g} / \mathrm{cc} \\
& \frac{M}{L}=7.85 *_{\frac{\Pi}{4}} *\left(25.4^{2}-22.2^{2}\right)=9.3863 \mathrm{gm} / \mathrm{cm}^{2}
\end{aligned}
$$

ii) For AISI 1020 (2mm thickness)

$$
\begin{gathered}
\rho=7.87 \mathrm{~g} / \mathrm{cc} \\
\frac{M}{L}=7.87 * \frac{\Pi}{4} *\left(25.4^{2}-22.4^{2}\right) \\
=11.5651 \mathrm{gm} / \mathrm{cm}^{2}
\end{gathered}
$$

iii) For AISI 4130 (1.6mm thickness)

$$
\rho=7.85 \mathrm{gm} / \mathrm{cc}
$$

$$
\frac{M}{L}=7.85 *_{\frac{\Pi}{4}} *\left(25.4^{2}-22.2^{2}\right)=9.3863 \mathrm{gm} / \mathrm{m}^{2}
$$

\section{B. CALCULATION OF BENDING STRENGTH AND BENDING STIFFNESS}

According to the bending moment equation, the

Bending strength $=\frac{s_{y}(I)}{y}$

Bending stiffness- $\mathrm{E}^{*} \mathrm{I}$

Material calculation: -

- $\quad$ For AISI 1018 (1.6mm thickness)

$$
\begin{gathered}
\text { Bending strength }=\frac{365\left(\frac{\pi}{64}\left(25 \cdot 4^{4}-22 \cdot 4^{4}\right)\right.}{\left(\frac{25 \cdot 4}{2}\right)} \\
=244420.71 \mathrm{~N}-\mathrm{mm}
\end{gathered}
$$

Bending stiffness

$=205\left(\frac{\pi}{64}\left(25 \cdot 4^{4}-22 \cdot 4^{4}\right)\right)=1743 \mathrm{~N}-\mathrm{mm}^{2}$

- $\quad$ For AISI 1020 (2mm thickness)

$\begin{aligned} \text { Bending strength }= & \frac{420\left(\frac{\pi}{64}\left(25 \cdot 4^{4}-21 \cdot 4^{4}\right)\right.}{\left(\frac{25 \cdot 4}{2}\right)} \\ & =335060.9 \mathrm{~N}-\mathrm{mm}\end{aligned}$ 
Bending stiffness

$$
\begin{aligned}
=190\left(\frac{\pi}{64}\left(25 \cdot 4^{4}-22 \cdot 4^{4}\right)\right) \\
=1925.98 \mathrm{~N}-\mathrm{mm}^{2}
\end{aligned}
$$

For AISI 4130 (1.6mm thickness)

Bending strength $=\frac{460\left(\frac{\pi}{64}\left(25 \cdot 44^{4}-21 \cdot 4^{4}\right)\right.}{\left(\frac{25 \cdot 4}{2}\right)}$

Bending stiffness

$$
=308037 \mathrm{~N}-\mathrm{mm}
$$

$$
\begin{aligned}
&=210\left(\frac{\pi}{64}\left(25 \cdot 44^{4}-22 \cdot 24^{4}\right)\right) \\
&= 1785 \mathrm{~N}-\mathrm{mm}^{2}
\end{aligned}
$$

Table 4: bending strength and bending stiffness of three materials

\section{FINITE ELEMENT ANALYSIS (FEM)}

Meshing has been carried out for several materials in ANSYS software.

\begin{tabular}{|c|c|}
\hline COMPONENTS & VALUE \\
\hline MESH SIZE & 4 \\
\hline MESH METHOD & Tetrahedron \\
\hline NO.OF ELEMENTS & 136893 \\
\hline NO. OF NODES & 273240 \\
\hline IMPACT FORCE & $4 \mathrm{G}, 2.5 \mathrm{G}$ \\
\hline
\end{tabular}

Table 5: Summary of mesh data

A frame of the automobile assumes the most crucial role in the wellbeing of a passenger. The frame contains the operator, motor, brake system, steering mechanism, and suspension system. So, the frame must possess adequate strength to protect the passengers in the event of an impact. Static structural analysis is a FEM technique used to examine the response of real structures to internal and external loads. CAE analysis on the frame is performed to evaluate the safety offered by the chassis to drivers in the event of an accident, including rear impact, side-impact, and frontal impact.

\section{A) FRONTAL IMPACT ANALYSIS:}

It is the impact wherein there is a possibility of a vehicle crashing into another vehicle head-on during the race.

i. Assumptions and Considerations taken for the frontal impact analysis are:

$>$ The mass of the vehicle with drivers is $154.24 \mathrm{~kg}$.

$>$ Constraints are like the force is applied at the frontmost point in a front impact, and wheels are fixed.

$>$ We consider chassis is in static condition

ii. Calculation of Impact Forces:

As mentioned, Front-impact force should be $4 \mathrm{G}$.

Where $\mathrm{G}$ force is the product of mass and gravity.

The total mass of the vehicle including driver $=154.24 \mathrm{~kg}$ $\mathrm{F}=4 \mathrm{G}=4 \times$ totalmass $\times$ gravity $\mathrm{F}=4 \times 154.24 \times 9.81=6052.38 \mathrm{~N}$

B) REAR IMPACT ANALYSIS

i. Assumptions and Considerations taken for the rear impact analysis are:

$>$ Mass of vehicle with drivers is $154.24 \mathrm{~kg}$

$>$ Constraints are like wheels are fixed, and force is applied back most point in a rear impact.
$>$ We consider chassis is in static condition for rear impact, considering the worst-case collisions. The force of rear impact is less when compared to the front impact.

\section{ii. Calculation of Impact Forces:}

For the rear impact, the force is $2.5 \mathrm{G}$.

$\mathrm{F}=2.5 \mathrm{G}=2.5 \times$ Total mass $\times$ gravity

$\mathrm{F}=2.5 \times 154.24 \times 9.81=3782.74 \mathrm{~N}$

\section{* SIDE IMPACT ANALYSIS}

The side impact analysis is carried out as there is a chance of collision with another vehicle from either direction.

i. Assumption \& considerations:

$>$ Mass of vehicle with drivers is $154.24 \mathrm{~kg}$

$>$ Constraints are like wheels are fixed, and force is

\begin{tabular}{|l|l|l|}
\hline Material & $\begin{array}{l}\text { Bending strength } \\
(\mathbf{N}-\mathbf{~ m m})\end{array}$ & $\begin{array}{l}\text { Bending stiffness } \\
\left(\mathbf{N}-\mathbf{~ m m}^{\mathbf{2}}\right)\end{array}$ \\
\hline AISI 1018 & 244420.71 & 1743 \\
\hline AISI 1020 & 335060.9 & 1925.98 \\
\hline AISI 4130 & 308037 & 1785 \\
\hline
\end{tabular}

applied at side most point in a side impact.

$>$ We consider chassis is in static condition

ii. Calculation of Impact Forces:

The impact force is given as $4 \mathrm{G}$.

$\mathrm{F}=2.5 \mathrm{G}=4 \times$ total mass $\times$ gravity

$\mathrm{F}=2.5 \times 154.24 \times 9.81=3782.74 \mathrm{~N}$

VII. RESULTS AND DISCUSSION

A) FRONTAL IMPACT ANALYSIS

1. AISI 4130, Circular Cross-section $(25.4 * 22.2 * 1.6 \mathrm{~mm})$

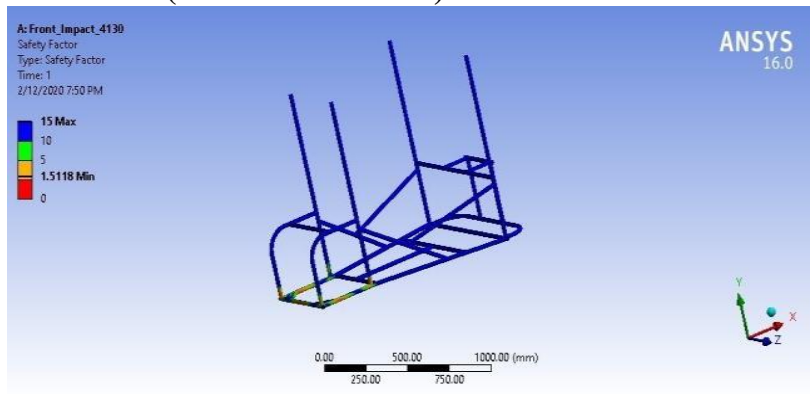

Figure 6: Factor of safety

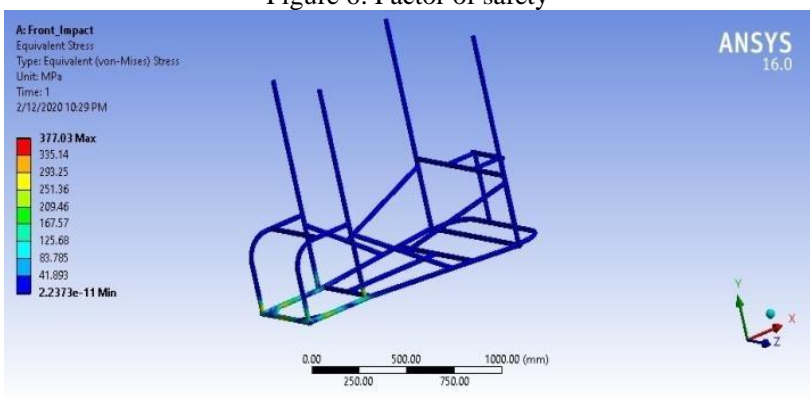

Figure 7: Equivalent stress 


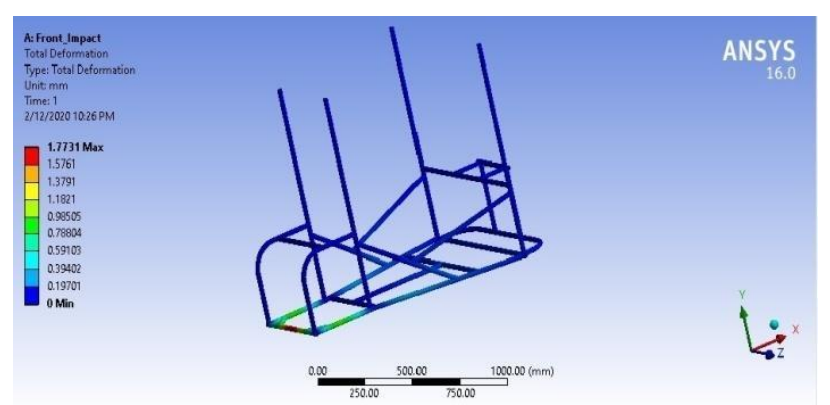

Figure 8: Total deformation

RESULTS:

\begin{tabular}{|c|c|}
\hline Factor of safety (FOS) & 1.5118 \\
\hline Total deformation (T.D) & $1.7731 \mathrm{~mm}$ \\
\hline Equivalent stress (Eq. Stress) & $377.03 \quad \mathrm{MPa}$ \\
\hline
\end{tabular}

Table 6: Frontal impact results for AISI 4130

\section{AISI 1018; Circular cross section $(25.4 * 22.2 * 1.6 \mathrm{~mm})$}
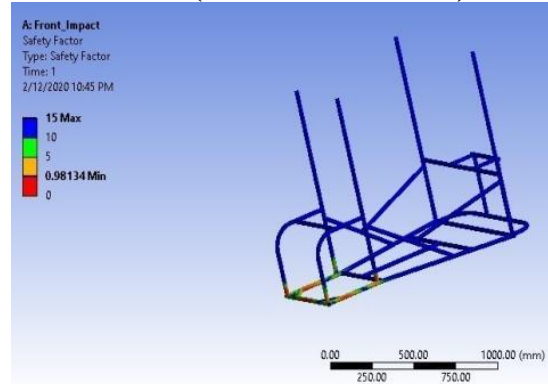

Figure 9: Factor of safety

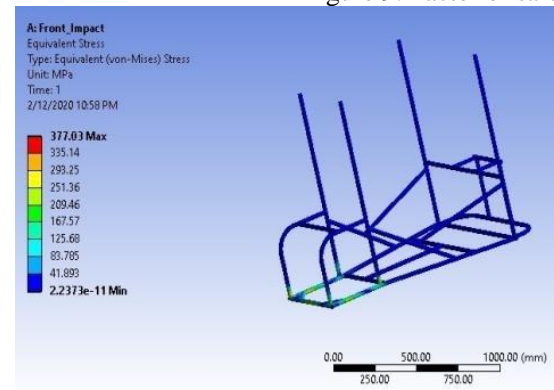

ANSYS

Figure 10: Equivalent stress
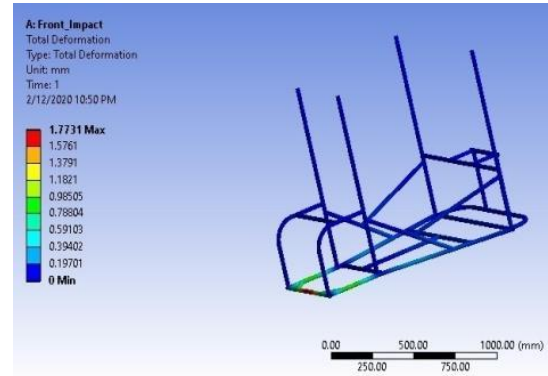

Figure 11: Total deformation RESULTS:

\begin{tabular}{|c|c|}
\hline \multicolumn{2}{|c|}{ RESULT: } \\
\hline Fator of safety & 0.98134 \\
\hline Equivalent stress & $1.7731 \mathrm{~mm}$ \\
\hline
\end{tabular}

Table 7: Frontal impact results for AISI 1018

\section{AISI 1020; Circular cross-section $(25.4 * 21.4 * 2 \mathrm{~mm})$}
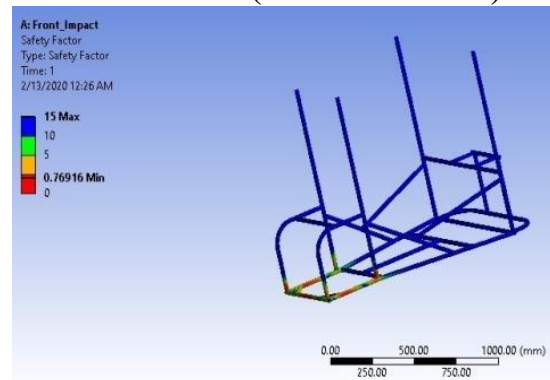

ANSYS

Figure 12: Factor of Safety

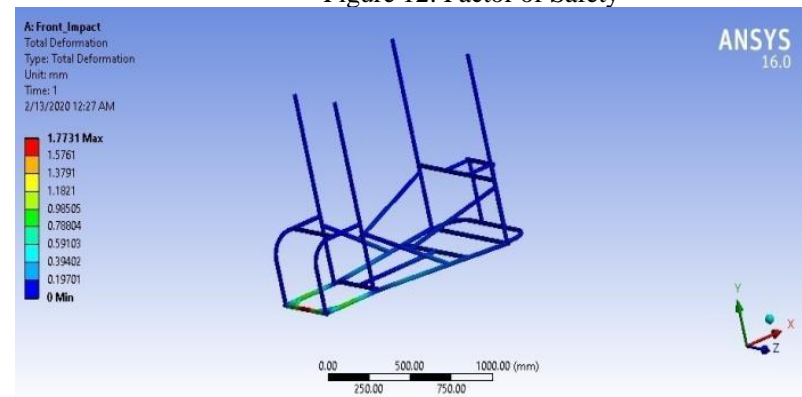

Figure 13: Total deformation

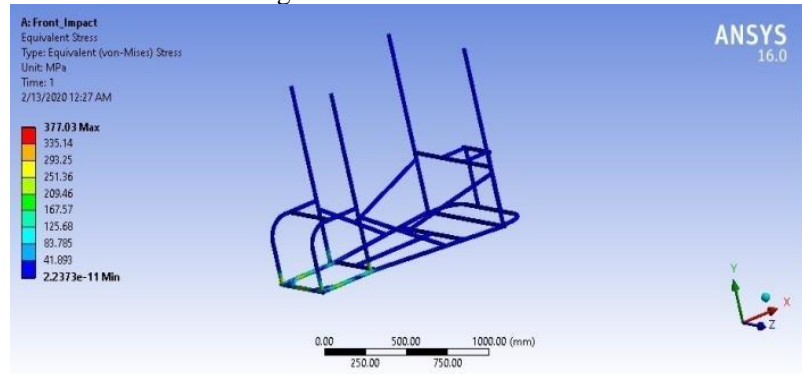

Figure 14: Equivalent stress

\begin{tabular}{|l|c|} 
Results: \\
\begin{tabular}{|l|c|}
\hline Factor of safety & 0.76916 \\
\hline Total deformation & $1.7731 \mathrm{~mm}$ \\
\hline Equivalent stress & $377.03 \mathrm{MPa}$ \\
\hline
\end{tabular}
\end{tabular}

Table 8: Frontal impact results for AISI 1020

\section{B) REAR IMPACT ANALYSIS \\ 1) AISI 4130; Circular cross-section} $(25.4 * 22.2 * 1.6 \mathrm{~mm})$

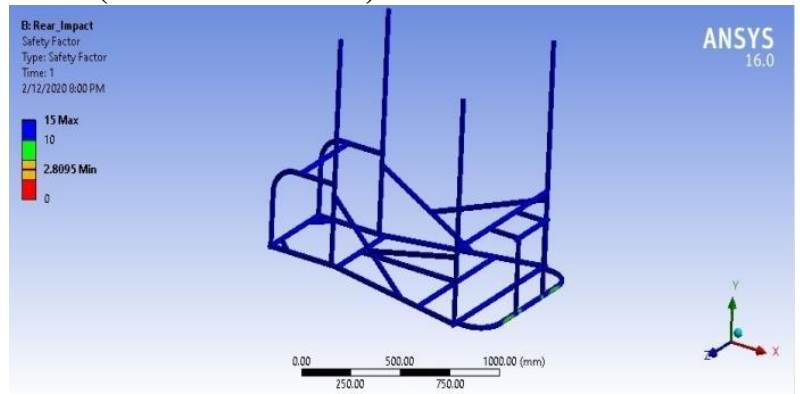

Figure 15: Factor of safety 


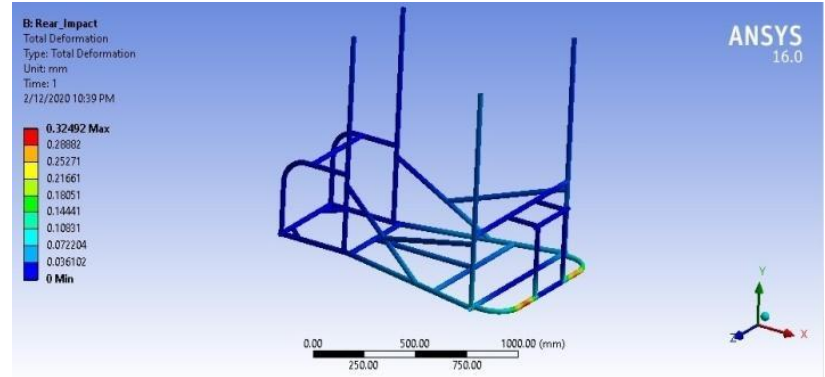

Figure 16: Total deformation

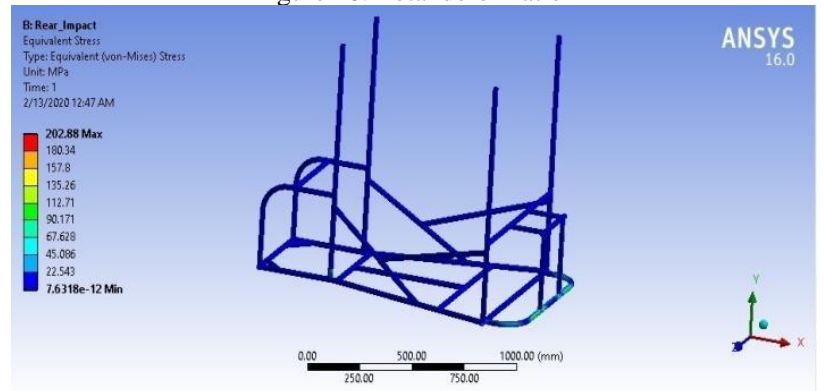

Figure 17: Equivalent stress Results:

\begin{tabular}{|c|c|}
\hline Factor of safety & 2.8095 \\
\hline Total deformation & $0.32492 \mathrm{~mm}$ \\
\hline Equivalent stress & $202.88 \mathrm{MPa}$ \\
\hline
\end{tabular}

Table 9: Rear impact results for AISI 4130

2) AISI 1018; Circular cross-section $(25.4 * 22.2 * 1.6$ mm)
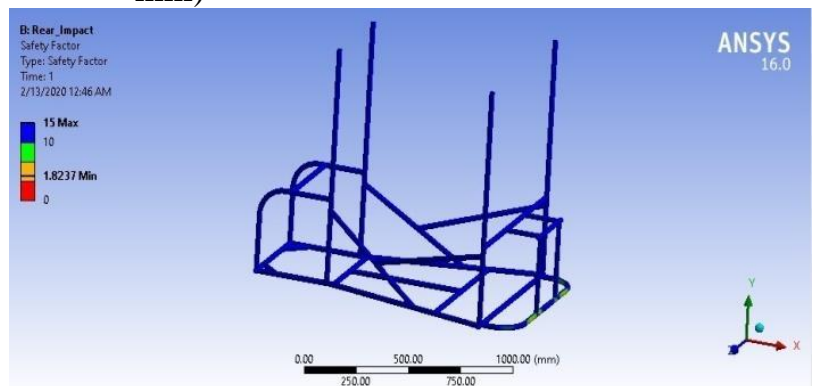

Figure 18: Factor of safety Figure 19: Total deformation
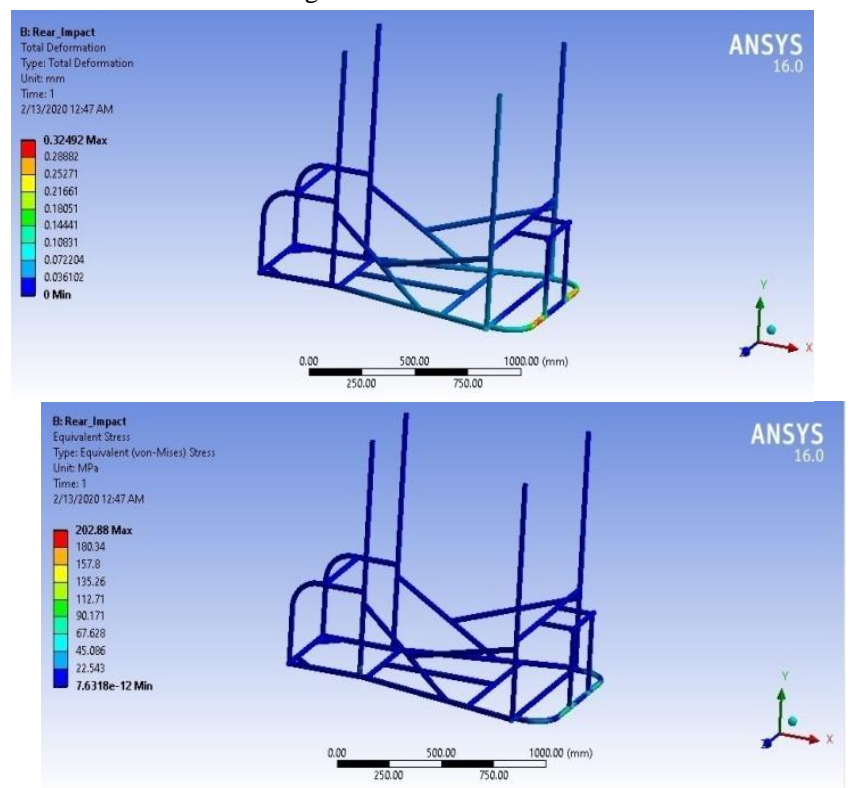

Figure 20: Equivalent stress Results:

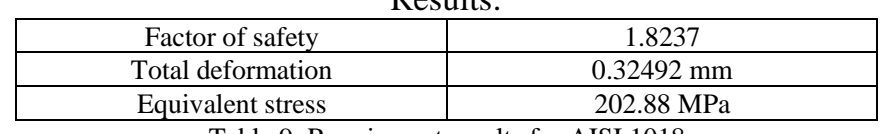

Table 9: Rear impact results for AISI 1018

3) AISI 1020; Circular cross-section $(25.4 * 21.4 * 2 \mathrm{~mm})$
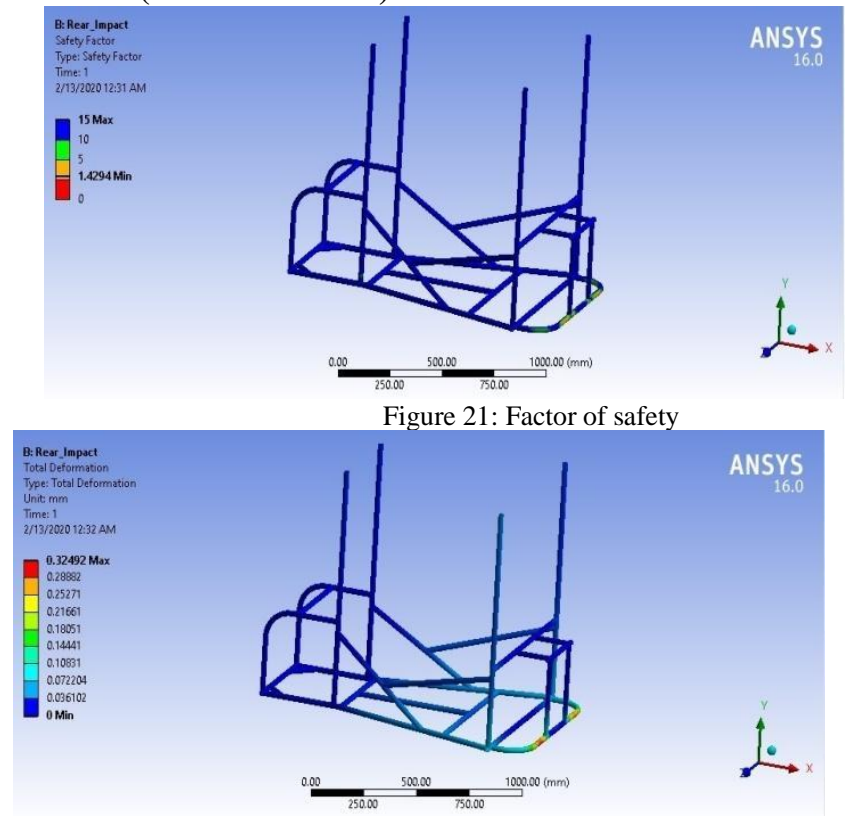

Figure 22: Total deformation

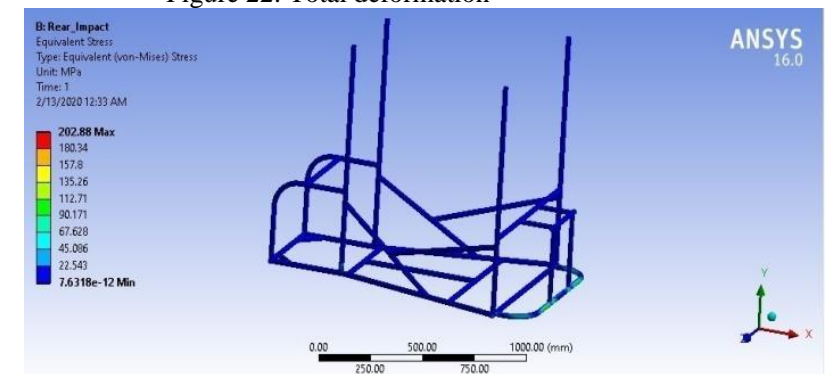

Fig-22: Equivalent stress

\begin{tabular}{|c|c|}
\multicolumn{2}{|c|}{ Results: } \\
\hline Factor of safety & 1.4294 \\
\hline Total deformation & $0.32492 \mathrm{~mm}$ \\
\hline Equivalent stress & 202.88 \\
\hline
\end{tabular}

Table 10: Rear impact results for AISI 1020

C) SIDE IMPACT ANALYSIS

1) AISI 4130; Circular cross-section $(25.4 * 22.2 * 1.6 \mathrm{~mm})$

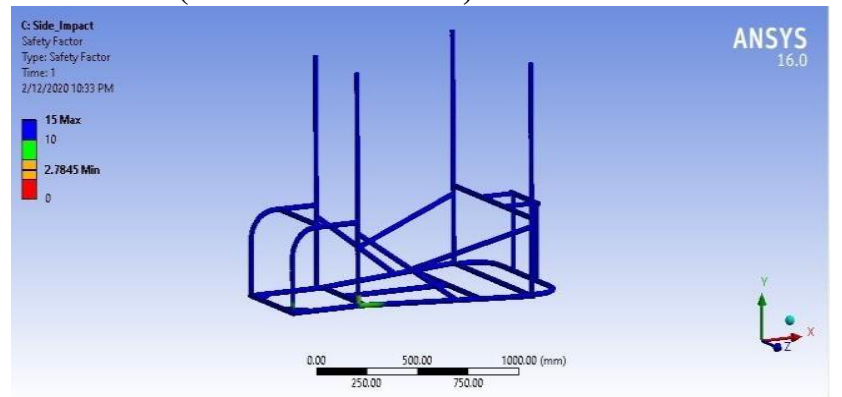

Figure 23: Factor of safety 


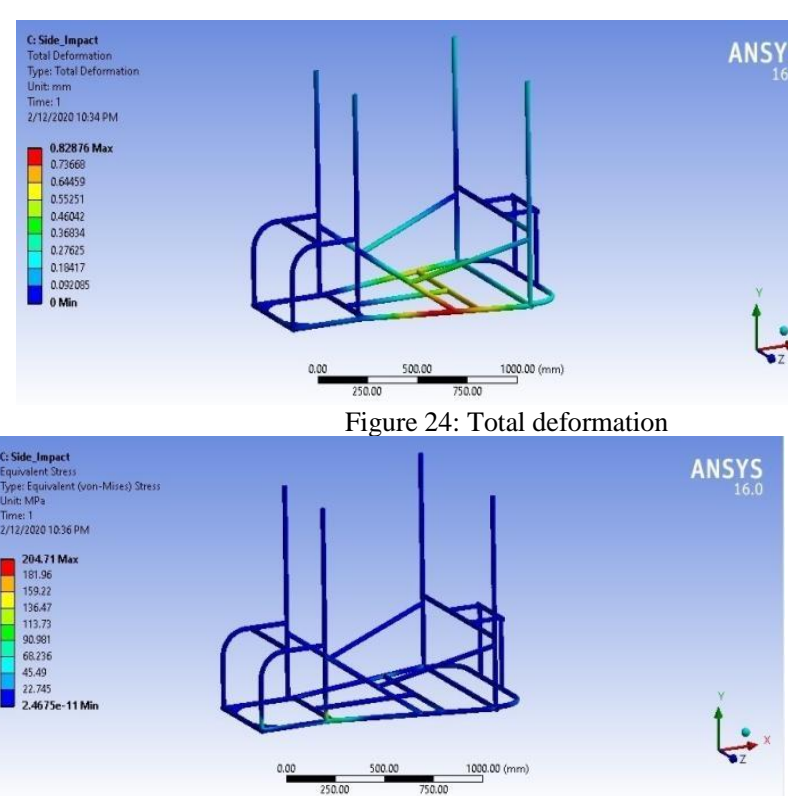

Figure 25: Equivalent stress

\begin{tabular}{|l|l|}
\multicolumn{2}{c}{ Results: } \\
\begin{tabular}{|l|l|}
\hline Factor of safety & 2.7845 \\
\hline Total deformation & $0.82876 \mathrm{~mm}$ \\
\hline Equivalent stress & $204.71 \mathrm{MPa}$ \\
\hline
\end{tabular}
\end{tabular}

Table 11: Side impact results for AISI 4130

2) AISI 1018; Circular cross section $(25.4 * 22.2 * 1.6 \mathrm{~mm})$

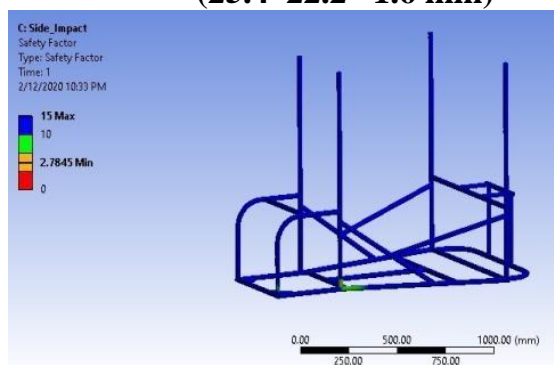

Figure 26: Factor of safety

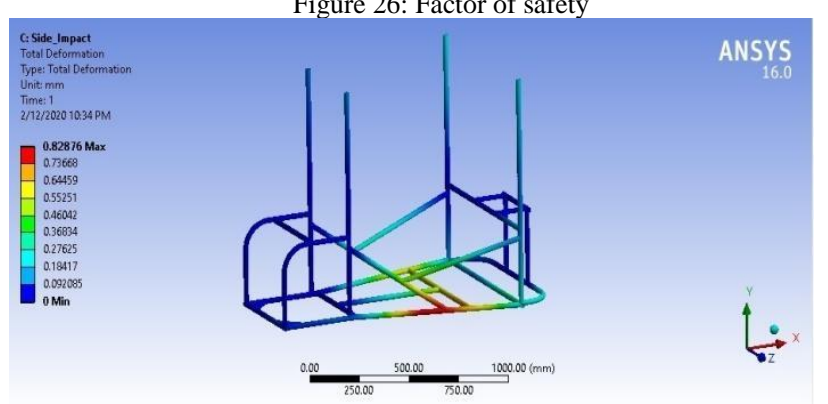

Figure 27: Total Deformation

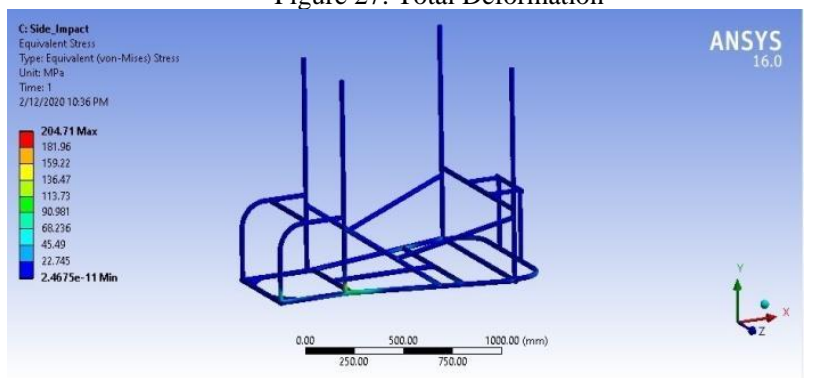

Figure 28: Equivalent stress

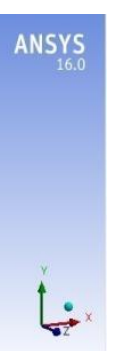


- The deformation \& stresses are under the limit. The factor of safety (FOS) is under the safety limit for all the subsystems

- Based on the above CAE results and other parameters like cost, weight, and availability, we have decided to go with AISI 4130 upon considering the various factors, including the factor of safety, total deformation, equivalent stress, and also the availability of the materials compared to other metal.

- The total deformation is least for AISI 4130 is better when compared to other grades.

- The factor of safety is more for AISI 4130 for given loading conditions.

- Appreciable ergonomics has been accomplished in the design with a base weight of Solar Vehicle.

- Reducing weight improves the fuel efficiency of the solar car.

\section{REFERENCES}

[1] Rules and Regulation of ISIE's Electric Solar Vehicle Championship 2016.

[2] Mohd Azizi Muhammad Nora, Helmi Rashida, Wan Mohd Faizul Wan Mahyuddin, Mohd Azuan Mohd Azlanc, Jamaluddin Mahmud, 'Stress analysis of a low loader chassis,' International Symposium on Robotics and Intelligent Sensors 2012 (IRIS 2012) 